Malaeb, Z. and Hamzeh, F. (2018). "A Lean Perspective of Stakeholder Integration in Public Private Partnerships." In: Proc. $26^{\text {th }}$ Annual Conference of the International. Group for Lean Construction (IGLC), González, V.A. (ed.), Chennai, India, pp. 3-12. DOI: doi.org/10.24928/2018/0217. Available at: www.iglc.net.

\title{
A LEAN PERSPECTIVE OF STAKEHOLDER INTEGRATION IN PUBLIC PRIVATE PARTNERSHIPS
}

\author{
Zeina Malaeb ${ }^{1}$ and Farook Hamzeh ${ }^{2}$
}

\begin{abstract}
The Special Purpose Vehicle (SPV) is the party representing the private sector in a Public Private Partnership (PPP), and combines a number of stakeholders including equity shareholders, designers, contractors, and service providers under one umbrella. Consequently, the key to ensuring successful project delivery is achieving an efficient integration of the different SPV stakeholders involved, to deliver the project as a unified entity. However, the SPV's stakeholder management role is highly under-investigated in the literature, and no studies have attempted to explore SPV stakeholder integration. This highlights a significant need to do so, considering that the former is both a prerequisite and a driver of PPP project success. This research aims to address this need through generating a list of SPV characteristics that reflect stakeholder collaboration and developing Critical Success Factors (CSFs) to measure the level of SPV stakeholder integration, based on concepts projected from the Integrated Project Delivery (IPD) system. The aforementioned factors relate to the project's organization structures, commercial frameworks, and operating systems and processes. This research is the first of its kind that aims to investigate the SPV's integration level, from a holistic IPD perspective, as an enabler of successful relationship management.
\end{abstract}

\section{KEYWORDS}

Collaboration, Critical Success Factors (CSFs), Integrated Project Delivery (IPD), Public Private Partnership (PPP), Stakeholder Integration.

\section{INTRODUCTION}

A Public Private Partnership (PPP) describes a procurement route that involves two main entities, the public sector and the private sector, for the provision of a public asset or service. PPP projects offer a range of benefits as they allow the public sector to utilize the private sector's skills and expertise in project delivery and benefit from private financing,

1 Graduate Student, Department of Civil and Environmental Engineering, American University of Beirut, Beirut, Lebanon, +96176701078, zmm17@ mail.aub.edu

2 Assistant Professor, Department of Civil and Environmental Engineering, American University of Beirut, Beirut, Lebanon, +96170680523, fh35@aub.edu.lb 
on one hand, and offer improvements in project implementation time, whole life-cycle costs, and service quality, on the other (Leiringer, 2006; Liu et al., 2015). Being different from traditional project delivery routes, PPPs encompass a number of distinct features, stemming from their long-term nature, bundling of project functions, complex contractual agreements, and distinct risk allocation formulas (Grimsey and Lewis, 2004). A fundamental characteristic of a PPP is the presence of the Special Purpose Vehicle (SPV), which is the project company representing the private sector, formed especially to undertake the PPP project. This entity takes responsibility for the project through its financing, design, construction and subsequent operation and maintenance stages, over a long period of time (20-30 years) (Gomez and Gambo, 2016). In order to fulfil these functions, the SPV is structured as a consortium, combining under one umbrella a number of key stakeholders, mainly equity shareholders, designers, construction contractors, and operations and maintenance contractors. Significantly, the combination of stakeholders under one SPV calls for several unique features, namely: early stakeholder involvement, alignment of stakeholder goals and interests, stakeholder integration, collaborative working, innovation potential, and long-term commitment, among others (Fischbacher and Beaumont, 2003; Leiringer, 2006; Sainati et al., 2017).

Both the PPP delivery system and the SPV procurement structure necessitate that the aforementioned stakeholders collaborate together to deliver the project successfully as an integrated team. PPP project success is strongly affected by the level of stakeholder integration as PPPs necessitate solid collaboration for successful service delivery. Evaluating PPP success therefore requires a comprehensive evaluation of the SPV team, specifically in terms of stakeholder integration. However, the SPV's stakeholder management role is highly under investigated in the literature and there exists a gap regarding its internal stakeholder relationships and interactions. In fact, PPP researchers state that project management studies have never focused expressively on SPVs and the existing literature fails to efficiently address inherent relational matters, as there is a lack of knowledge concerning PPP stakeholders (McErlane et al., 2016; Sainati et al., 2017). Therefore, there is a need to investigate and evaluate the efficiency of the SPV's management role, in terms of stakeholder integration, seeing that it is both a driver and a prerequisite for PPP project success. Considering the significance of stakeholder integration for the SPV, and thus its connection to the Integrated Project Delivery (IPD) system, added to the fact that literature on the latter is rich with research on integration, there is an opportunity for projecting such concepts onto the SPV evaluation framework.

This research aims to address this need through identifying the core characteristics of SPV procurement that reflect stakeholder collaboration and correlate it to integrated project delivery, and developing Critical Success Factors (CSFs) to measure the level of SPV stakeholder integration, based on concepts projected from the IPD system. The aforementioned factors relate to the project's organization structures, commercial frameworks, and operating systems and processes. This research is the first of its kind that aims to investigate the SPV's integration level, from a holistic IPD perspective, as an enabler of successful relationship management. This paper first presents the adopted research methodology. Following, the main features of SPV project delivery and its correlation to integrated project delivery systems are delineated. Next, the paper discusses 
the three fundamental families that contribute to integrated project delivery systems: organization structures, commercial frameworks, and operating systems and processes. Finally, the identified critical success factors are presented, classified, and linked as per the three aforementioned families.

\section{RESEARCH OBJECTIVES AND METHODOLOGY}

The objectives of this research are two-fold: identifying features of PPP projects that tie them to integrated project delivery systems, and developing a list of CSFs to measure SPV stakeholder integration. The research methodology is delineated in Figure 1 below. After identifying the main SPV characteristics, CSFs that serve as indicators of SPV stakeholder integration are developed. The main studies used as a basis for collecting and generating CSFs are: Aapaoja et al. (2013), Baiden et al. (2006), Cheung et al. (2006), Ibrahim et al. (2013), and Thomsen et al. (2009). The final CSFs are then filtered, grouped, and sorted in terms compatible with SPV project delivery as under the project delivery system's organization structures, commercial frameworks, and operating systems and processes.

Literature

review on

PPP project

delivery, IPD

systems, and

project and

stakeholder

integration.
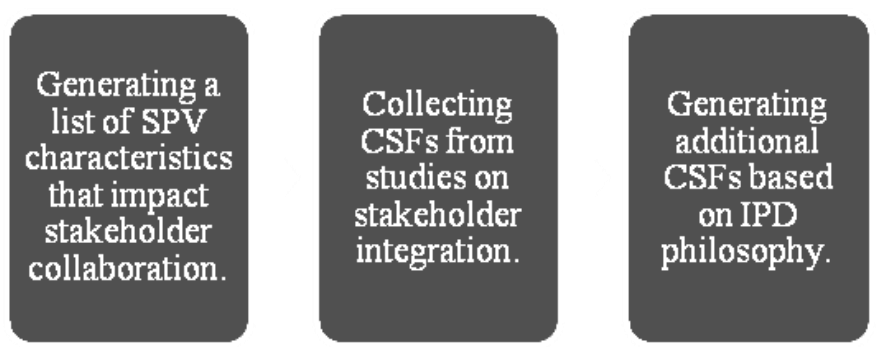

Filering,

grouping, and

sorting the

final CSFs

under the

three IPD

foundations.

Figure 1: Research Methodology

\section{CHARACTERISTICS OF THE SPECIAL PURPOSE VEHICLE (SPV)}

SPV project delivery is characterized by several distinct features which impact stakeholder collaboration and correlate it to integrated project delivery systems. These collaboration characteristics are mapped and linked to inherent features of PPP projects in this section.

\section{ALIGNMENT OF STAKEHOLDER GOALS AND INTERESTS}

The SPV design enables better alignment of stakeholder interests, as a function of the both its contractual schemes and stakeholder organization structures (Sainati et al, 2017). The primary reason driving this alignment of interests is the involvement of the major stakeholders, mainly the Design-Build (DB) contractor and Operations and Maintenance $(\mathrm{O} \& \mathrm{M})$ contractor, in project financing. This approach necessitates that contractors and service providers sponsor the SPV and take stakes in it as a sign of committing to the PPP project. Involving the contractors in project funding is equivalent to strengthening their association with the project. This generates a connectivity between project funders and 
service providers, and bridges the gap between them. In addition, as the SPV is to operate the project for a long period of time after construction, it would be acting as a quasiproject-owner during that period. Consequently, the roles of "project owner", "project contractor", and "project operator" become integrated, within the SPV structure. This would instigate the SPV to consider what is best for the project during the design and construction stages, as it bears the resulting consequences throughout project operation. Additionally, as all the major stakeholders on the project are incorporated under the umbrella of this SPV and deliver the project as one unified body, an environment of joint responsibility and shared risk management is created. This not only causes the alignment of interests between the different key stakeholders, but also causes their alignment with the overall project interests, which is of even greater importance.

\section{WHOLE-LIFE CYCLE APPROACH}

The whole-life cycle approach adopted by the SPV shareholders is a function of three main features: designing for service delivery, bundling project functions, and long term contracts.

\section{Design for Service Delivery}

PPP projects encompass a feature that goes past the mere delivery of an asset, but rather focuses on the delivery of a continuous service (Grimsey and Lewis, 2004; World Bank, 2009). The main distinction that characterizes service delivery performance is its requirement for considering serviceability issues in the design phase of the project, since this initial phase affects all the consequent phases, primarily in terms of costs (Tranfield et al, 2005). Therefore, the SPV, in designing for the delivery of the required service, would adopt whole-life cycle costing.

\section{Bundling Project Functions}

A main feature of PPPs is the bundling of major project phases or functions (World Bank, 2017). This refers to the combination of the design, construction, and operations and maintenance stages in specific. This bundling encourages the SPV to consider implications of its decisions on different stages of the project which leads to the adoption of whole-life cycle costing (Chan and Cheung, 2014; World Bank, 2009). Therefore, the optimization of costs is happening at the overall project level instead of the individual

phase levels. In lean terms, this is a shift from the traditional concept of transformation and local optimization to the global perspectives of flow and value generation.

\section{Long Term Contracts}

PPP projects are characterized by the long-term nature of their contracts. These long term commitments act as incentives for the private party to account for service delivery cost when designing the project. A long-term contract generates a longer term commitment, which places capital at risk and is presumed to force the private stakeholders to produce a facility that is durable and functional while minimizing life cycle costs (Leiringer, 2006). 


\section{COLLABORATIVE ENVIRONMENTS}

PPP projects create collaborative environments, stemming mainly from the early involvement of stakeholders, design for service delivery, and the organization structure of the SPV.

\section{Early Stakeholder Involvement}

One distinctive feature of PPP projects is the early involvement of all key stakeholders in project delivery. In other words, from day one, the designer, constructor, and operator, are all on board in the SPV. Involving participants early on has been associated with a number of advantages. For instance, it allows for synthesis in planning the design and implementation stages, as their separation has proven to significantly reduce the potential of enhancing project performance (Fischbacher and Beaumont, 2003). This permits the provision of input by downstream participants into upstream design and construction stages. In addition, this removes organizational barriers to facilitate the flow of information across boundaries, cross-organizational thinking, and collective problem solving. Moreover, through efficient inclusion, it is possible to develop a series of partnership benefits that include generating a holistic approach that improves service quality, encouraging innovation and creativity, and enhancing organizational learning through knowledge transfer (Fischbacher and Beaumont, 2003; Leiringer, 2006).

\section{Design for Service Delivery and SPV Structure}

Designing for service delivery necessitates high levels of team working, communication, and collaboration throughout the project, in order to optimize the continuous provision of services. PPP project success is highly dependent on the quality of integration and collaboration within the SPV organization. The structure of the SPV is characterized by involving the major project stakeholders under one umbrella. It is designed, in concept, to foster such integrative and cooperative efforts across the different teams involved to deliver successful outcomes.

\section{THE LINK BETWEEN PPP AND IPD}

The PPP characteristics discussed above bear significant association with those of integrated project delivery systems. PPP projects, and SPV functions in particular, seem to be founded on the concept of team integration as both a driver and prerequisite to project success. In fact, performance levels in infrastructure development are seen to depend as much on enhanced project cultures and integrated teamwork as they do on improved structures and systems (Kumaraswamy et al., 2007). PPPs, being of a long term nature, provide opportunities to generate, mature, and sustain cooperation and also for the benefits to materialize (Kumaraswamy and Anvuur, 2008). Furthermore, researchers have stressed on the need for close collaboration and team integration between PPP participants, citing formal incentive agreements as a driver for the former (Walker and Jacobsson, 2014). SPV stakeholder integration appears to be a fundamental cornerstone of the PPP delivery system, which brings forwards its correlation to other forms of collaborative project delivery. The IPD system is one such project delivery route that 
stresses the significance of stakeholder integration as a necessity for successful project delivery.

\section{FOUNDATIONS OF INTEGRATED PROJECT DELIVERY}

The IPD system describes that the factors for realizing efficient stakeholder integration stem from three foundations: organization structures, commercial frameworks, and operating systems and processes (Thomsen et al., 2009).

\section{Organization Structures}

IPD requires a drastic change in the organization structure through the formation of integrated teams. Key contractors are engaged early on and collaborate with the designer by providing input on cost, constructability, and value, with the goal of decreasing negative iterations throughout the design process. Stakeholders cooperate in making decisions and solving problems. This creates a "project culture" that encourages collaborative working as a unified integrated team. Another fundamental organizational feature of the IPD is what is termed the Core Group, an executive team responsible for the day-to-day management and leadership on a project. What is special about this team is that in integrates members from the different key stakeholders in the decision making process. These people do not only serve as managers, but also as leaders that are responsible for driving and committing to the IPD system. In IPD, project organizations change from silos to integrated, high performance teams. A transformation of the organization structure is the essential starting point to effectively implement an integrated form of project delivery (Thomsen et al., 2009).

\section{Commercial Frameworks}

The commercial structure on traditionally procured construction projects is built to drive the local optimization of individual stakeholders' interests, with each party looking out for its own well-being and disregarding others' interests. A key missing aspect is the alignment of stakeholder goals and objectives with the overall project objectives. In order to ensure this alignment is in place, a commercial framework is required that addresses the risk allocation and compensation structures amongst participants. For instance, the IPD contract calls for collective risk management, as opposed to each party managing its own risks. Through risk sharing, all the stakeholders actively collaborate in effectively identifying and collectively managing risks, which benefits the project as a whole. Another type of incentive introduced in these commercial frameworks is the "pain sharing and gain sharing" agreement. The idea is that all participating team members mutually share the risk of cost overruns and mutually benefit from cost savings in any part of the project. Again, this leads to a shift in mindset from each party looking out for itself to all parties looking out for the project. All involved stakeholders are part of one team with one goal, which is successful project delivery. The relationships between these major stakeholders shift from self-protecting and risk shifting to team-based ones, aligning the participants through incentives carefully chosen to encourage collective risk management and whole project optimization (Thomsen et al., 2009). 


\section{Operating Systems and Processes}

Even with integrated teams and sufficient commercial terms in place, operating systems and processes that either facilitate or hinder collaboration can make-or-break an integrated project delivery system. The systems that project stakeholders rely on must be integration-compatible and able to encompass stakeholder cooperation. Another requirement is utilizing technologies to ensure effective interaction and communication between project participants. In addition, certain project processes and mechanisms must exist that manage the interactions among stakeholders and nurture the integration potential of the project. These processes, which stem from the lean construction philosophy, promise to overcome the shortfalls of those employed in traditional project delivery systems. Examples of these processes are: integrated setting of project goals and objectives, collective decision making and integrated project management, collaborative planning with key project stakeholders, and involving the last planner in the planning process. These processes and systems must be designed to add value, foster collaboration, increase reliability, and allow for continuous improvement (Thomsen et al., 2009).

\section{DEVELOPED FACTORS}

The final set of developed factors, as belonging to the organization structures, commercial frameworks, and the operating systems and processes groupings, are presented in Figures 2, 3, and 4. These factors are inspired from research on project and stakeholder integration, as specified in the methodology section, and on concepts from the IPD philosophy as discussed above. They are further developed and grouped under the three families previously presented. They indicate general requirements to be adopted by PPP project delivery systems to achieve optimal stakeholder integration and also act as indicators of the actual integration level achieved on a project.

\section{CONCLUSION AND FUTURE WORK}

The features of the SPV, acting as a consortium combining the parties involved in PPP project delivery, bear significant similarities to the IPD system. Consequently, it is both interesting and significant to study this specific procurement route from a lean perspective, a topic no studies to date have focused on. This paper presents the main features of SPV procurement that correlate it to integrated project delivery and subsequently develops critical success factors to measure SPV stakeholder integration. This research is part of a wider thesis study that seeks to develop a comprehensive "SPV Health Check" tool, utilizing the aforementioned factors, to give an indicator of the level of integration within the SPV. Its contribution is noteworthy in introducing the lean vein into the PPP procurement route and evaluating PPP project success in terms of integration criteria. 


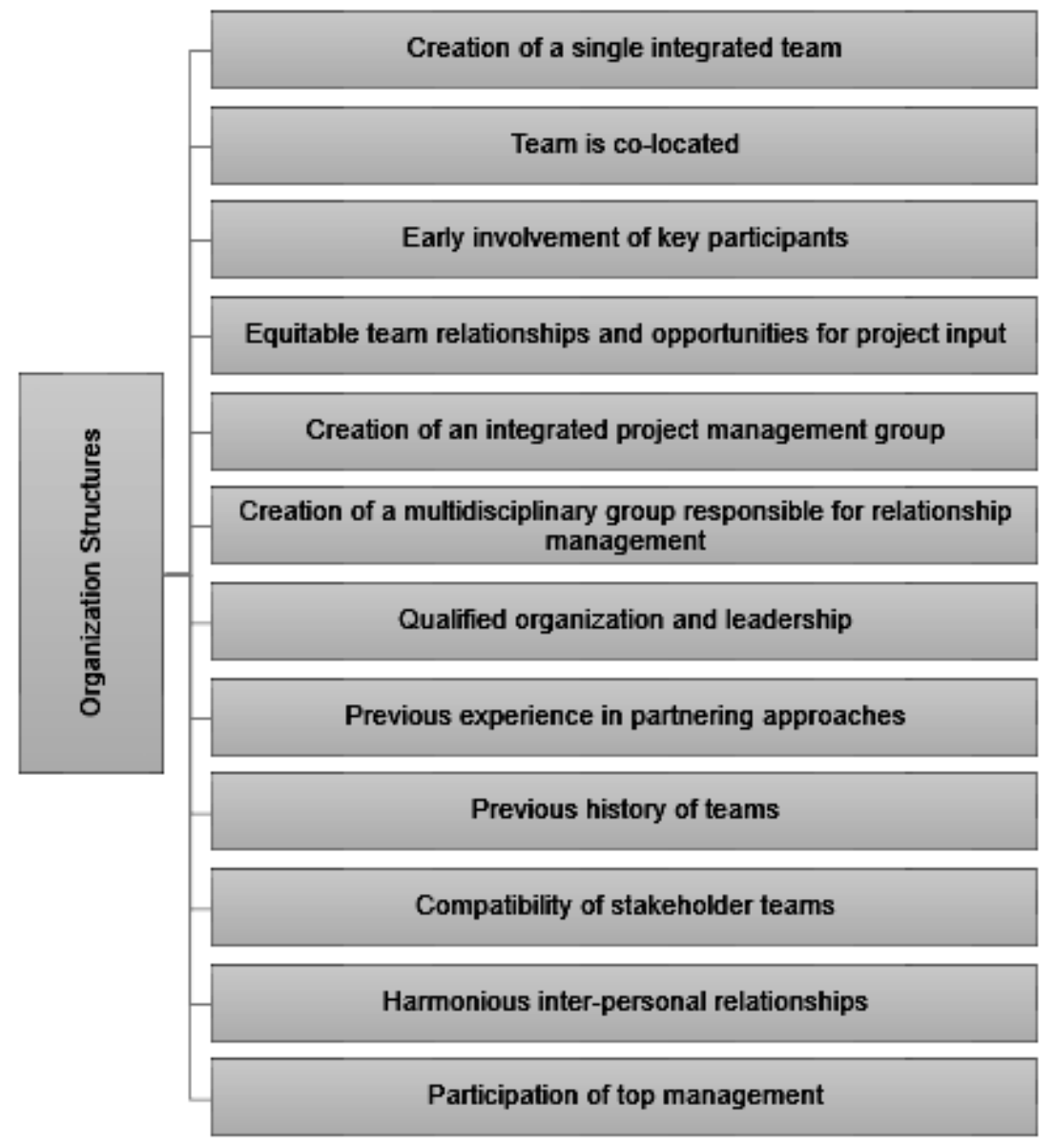

Figure 2: Factors under Organization Structures

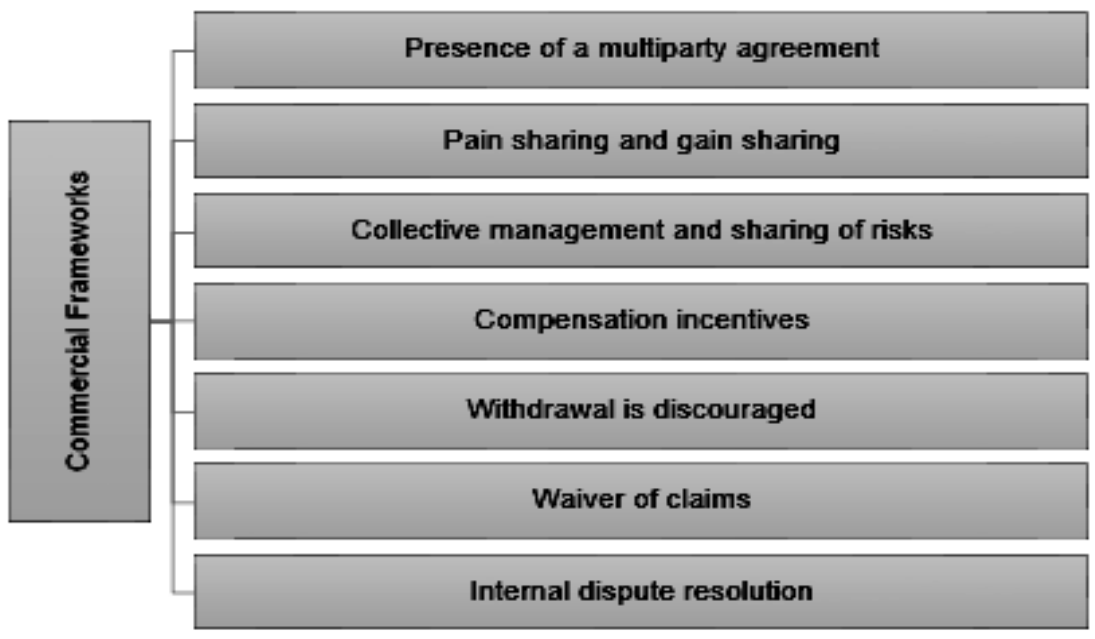

Figure 3: Factors under Commercial Frameworks 


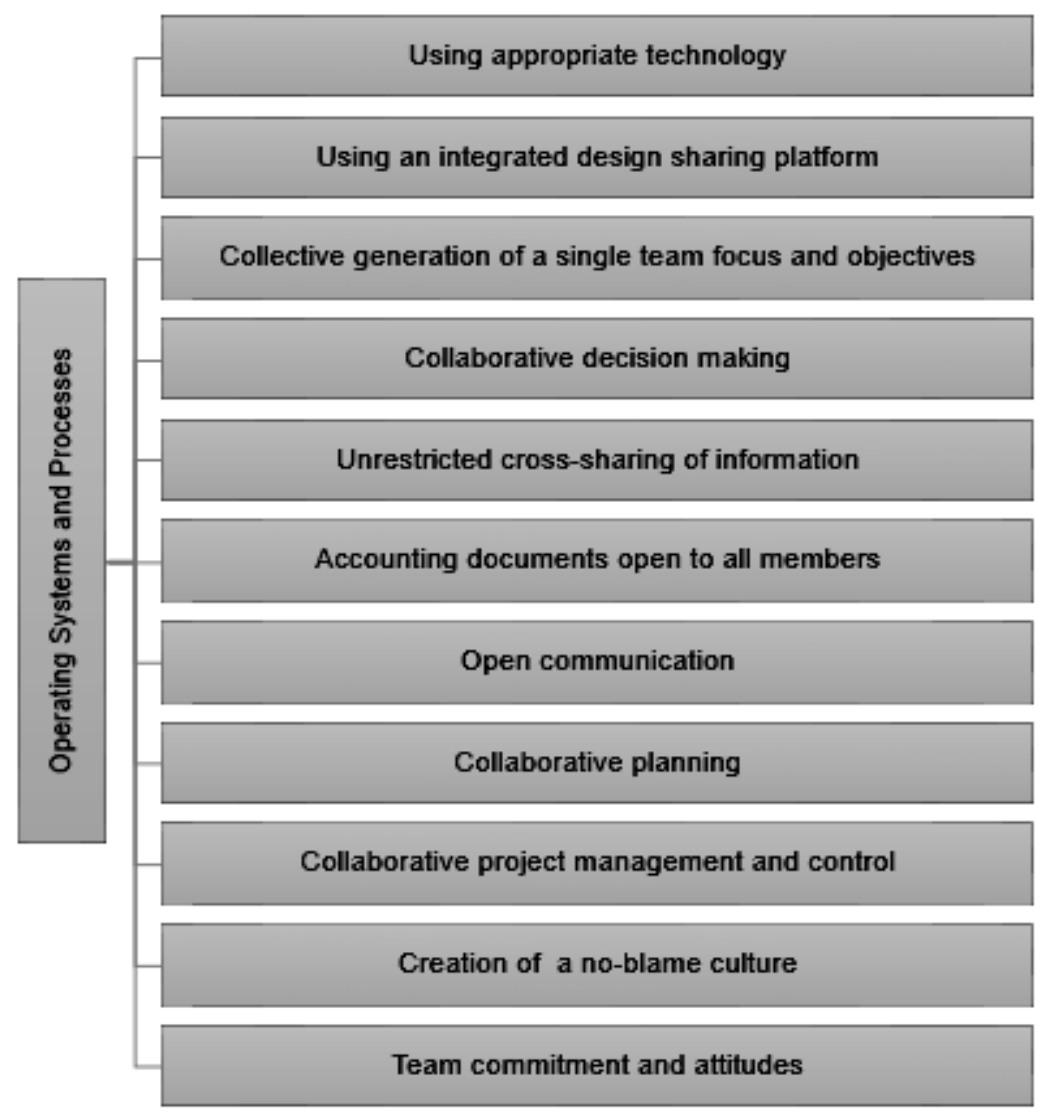

Figure 4: Factors under Operating Systems and Processes

\section{REFERENCES}

Aapaoja, A., Herrala, M., Pekuri, A., \& Haapasalo, H. (2013). The characteristics of and cornerstones for creating integrated teams. International Journal of Managing Projects in Business, 6(4), 695-713.

Baiden, B. K., Price, A. D., \& Dainty, A. R. (2006). The extent of team integration within construction projects. International Journal of Project Management, 24(1), 13-23.

Chan, A. P., \& Cheung, E. (2014). Public private partnerships in international construction: learning from case studies. Routledge.

Cheung, S. O., Yiu, K. T., \& Chim, P. S. (2006). How relational are construction contracts?. Journal of Professional Issues in Engineering Education and Practice, 132(1), 48-56.

Fischbacher, M., \& Beaumont, P. B. (2003). PFI, Public_-Private Partnerships and the Neglected Importance of Process: Stakeholders and the Employment Dimension. Public Money and Management, 23(3), 171-176.

Gomez, C., \& Gambo, M. (2016). Evaluation of Special Purpose Vehicle Organisation Skill Sets Taxonomy for Effective Public-Private Partnership Infrastructure Project Delivery. Journal of Construction in Developing Countries, 21(1), 147. 
Grimsey, D., \& Lewis, M. (2004). Public private partnerships: The worldwide revolution in infrastructure provision and project finance. Edward Elgar Publishing.

Ibrahim, C. K. I., Costello, S. B., \& Wilkinson, S. (2013). Development of a conceptual team integration performance index for alliance projects. Construction Management and Economics, 31(11), 1128-1143.

Kumaraswamy, M. M., \& Anvuur, A. M. (2008). Selecting sustainable teams for PPP projects. Building and Environment, 43(6), 999-1009.

Kumaraswamy, M. M., Ling, F. Y., Anvuur, A. M., \& Motiar Rahman, M. (2007). Targeting relationally integrated teams for sustainable PPPS. Engineering, Construction and Architectural Management, 14(6), 581-596.

Leiringer, R. (2006). Technological innovation in PPPs: incentives, opportunities and actions. Construction Management and Economics, 24(3), 301-308.

Liu, J., Love, P. E., Smith, J., Regan, M., \& Palaneeswaran, E. (2015). Review of performance measurement: implications for public-private partnerships. Built Environment Project and Asset Management, 5(1), 35-51.

McErlane, A, Heaney, G, Haran, M and McClements, S .(2016). The Application of Stakeholder Theory to UK PPP Stakeholders. In: P W Chan and C J Neilson (Eds.) Proceedings of the 32nd Annual ARCOM Conference, 5-7 September 2016, Manchester, UK, Association of Researchers in Construction Management, Vol 2, 863-872.

Sainati, T., Locatelli, G., \& Brookes, N. (2017). Special purpose entities in megaprojects: empty boxes or real companies? An ontological analysis. Project Manage. J, 48(2).

Thomsen, C., Darrington, J., Dunne, D., \& Lichtig, W. (2009). Managing integrated project delivery. Construction Management Association of America (CMAA), McLean, VA, 105.

Tranfield, D., Rowe, A., Smart, P. K., Levene, R., Deasley, P., \& Corley, J. (2005). Coordinating for service delivery in public-private partnership and private finance initiative construction projects: early findings from an exploratory study. Proceedings of the Institution of Mechanical Engineers, Part B: Journal of Engineering Manufacture, 219(1), 165-175.

Walker, D., \& Jacobsson, M. (2014). A rationale for alliancing within a public-private partnership. Engineering, Construction and Architectural Management, 21(6), 648673.

World Bank. (2009). Good Governance In Public Private Partnerships: A Resource Guide for Practitioners. Washington, DC: World Bank

World Bank. (2017). Public-Private Partnerships Reference Guide (Version 3). Washington, DC: World Bank 